\title{
Assessment of factors affecting willingness to blood donations among Hawassa town Population Southern, Ethiopia,2020.
}

Belete Girma ( $\sim$ beletegirma123@gmail.com )

SNNPR Health Bureau https://orcid.org/0000-0003-4714-5365

Hiwot Deneke ( $\sim$ beletegirma123@gmail.com )

Hawassa university Comprehensive specialized hospital

Yusuf Mohammed ( $\sim$ zakyu44@yahoo.com )

Oromia health bureau

\section{Research Article}

Keywords: Blood donation, Practice, Community, Ethiopia

Posted Date: April 9th, 2021

DOI: https://doi.org/10.21203/rs.3.rs-405943/v1

License: (c) (i) This work is licensed under a Creative Commons Attribution 4.0 International License.

Read Full License 


\section{Abstract}

Background: Blood donation remain a unique act to save the lives of people who encounter critical surgical and medical conditions. Since the request for blood supply is extremely high, a shortage of blood causes significant morbidity and mortality. To increase blood supply and maintain an adequate quantity of blood, regular and volunteer blood donation practice is needed. Ethiopia is one of the lowest annual donation rates which is $0.8 / 1000$ population. This study assesses factors affecting willingness to donate blood among Hawassa Town's southern Population.

Objectives: To assess the factors affecting willingness to blood donation among Hawassa town population Southern, Ethiopia.

Methods: A community-based cross-sectional investigation was conducted in Hawassa Town in November 2020. A multi-stage sampling procedure was utilized to select the study population. At Stage one, three Kebeles are taken from a total of 32 Kebele, at stage two implementing a systematically sampling method used to draw the total sample size, proportional to the population of each kebele and each study unit are selected randomly from Each household. Data were collected using a structured interviewer questionnaire. Data entered and analyzed using SPSS version 20.

Result: A total of 633 participants was included in the final analysis (response rate $=100 \%$ ). Among which 212(33.5\%) were female and 421 (66.5\%) were Male. The average age was $30.95 \pm 2.0$ years.Among the study participants, $490(77.4)$ are willing to donate blood in the future, and $125(22.9 \%)$ of them had blood donation practices in the past. The most prominent factors that affect the willingness of the participants for blood donation were, Unfit to donate, fear of needle prick and Not approached to donated $(45.2 \%, 38.5 \%$, and $11.7 \%)$ respectively. Most of the respondents $382(60.3 \%)$ reported that voluntary donor is the best source of protected blood. Desire to aid other and age of study Participant age greater 25 years are significantly associated factor for increased willingness to blood donated (AOR $2.146(0.028,0.753)$ and $(\mathrm{AOR}=1.8(95 \% \mathrm{Cl} 1.1,3.0)$ respectively.

Conclusion: Only minor proportion of the participants donated blood in the past, but Majority of the participant was willing to donate blood in the future. The crucial factors that participants are not willing to donate blood are Unfit to donate, fear of needle prick, and Not approached to donate. There is a need to improve awareness on who and when a person capable to donate blood and organizing campaigns to increase awareness on the importance of blood donation for those who are willing to donate blood in the future, to produce a pool of eligible blood donors.

\section{Background}

Blood is an essential element of human life and there are no substitutes for it (2). World Health Organization (WHO) proposes countries focus on young people to achieve $100 \%$ non-remunerated voluntary blood donation by 2020 Dhingra (1). Donated blood can be lifesaving for individuals who have lost considerable volumes of blood from terrible accidents, obstetric and gynecological hemorrhages or 
surgery and stem cell transplant patients. As well as for individuals who have symptomatic anemia from medical or hematologic conditions or cancers. Therefore, blood remains a crucial concern to society. The use of these lifesaving products may be complicated by infectious and immunological diseases some of which could be life-threatening (3). Blood donation constitutes the sole source of blood, but the recruitment of voluntary, non-remunerated donors is the most important challenge throughout the world (4). Blood remains the heart of life and is one of the most precious donations. Blood services are experiencing a shortage of blood all over the world. Demand for blood is rising worryingly, and current blood donation is inadequate to fulfil the demand (5). The sole source of blood is by blood donation (6). Universally, 80 million units of blood are provided each year, but only two million units are donated in subSaharan Africa where the need is extremely high (7). In sub-Saharan Africa (SSA), out of the estimated need of 18 million units of reliable blood per year, purely about $15 \%$ were collected (8). Adequate and safe blood supply has remained a challenge in developing countries like Ethiopia (9). In Ethiopia, there has been gross inadequacy and equitability in access to blood.

The national requirement for blood in Ethiopia is between 80,000 and 120,000 units per year but only $43 \%$ is collected (10).

Blood banks must provide adequate and reliable blood to the community. In most cases, donors are classified as voluntary, family replacement remunerated or paid donors, and autonomous donors. The risk of transfusion transmissible diseases is highest with the use of blood procured from remunerated donors. A person who lacks money is more likely to secrete his/her genuine state of health condition ( 3 , 18). Many studies have been conducted to determine people's knowledge, attitude, and practice of blood donation. However, factors motivating or discouraging blood donation are still in need of further investigation. Hence, this study was aimed to assess factors and blood donation practices among Hawassa town residents.

\section{Methods}

\section{Study design and study setting}

A community-based cross-sectional study was conducted to assess the factors affecting the willingness to donate blood among adults in Hawassa town in November 2020. Hawassa Town remain the capital city of southern nation nationality and people regional state and function as Sidama special zone. It is located $273 \mathrm{Km}$ from the capital of Ethiopia, Addis Ababa. According to the 2007 Census conducted by the principal statistical agency (CSA) of Ethiopia reports Hawassa town gains a aggregate population of 376,539 out of which 187,517 are Male and 189,022 are females. A total of 76,845 Households was estimated (8).

Source and study population

All adults aged 18 to 65 years residing in Hawassa Town were the source population. Those adults who were selected by multi-stage sampling technique and lived in the study area for at least six months were 
included. Study participants who experienced an acute illness during the data collection period and unable to hear were excluded from the study.

\section{Sample size determination}

The sample size (n) was calculated employing a formula for single population proportion: $n=Z 2 . a / 2 \times P(1-P)$ and the following assumptions: -

D2

Since there is no similar community-based study on Willingness for non-remunerated blood donations, a proportion of $50 \%$ was received to obtain the maximum sample size. $95 \%$ confidence interval, $5 \%$ margin of error and $10 \%$ added for possible non-response during the actual survey. The total sample size with a design effect of 1.5 was multiplied by the sample size calculated. $n=Z 2 . a / 2 \times P(1-P)=(1.96) 2$. $(0.5)(0.5)=384+10 \%=633$ Subjects

D2 (0.05)2

\section{Sampling techniques}

A multi-stage sampling technique was used to recruit the study participants. At stage one, three kebele (the most offensive administrative unit in Ethiopia) were selected from the total of 32 kebeles of the town by lottery method. At stage two, a systematic random sampling technique was employed to select households with proportional allocation to the size of the kebeles population. In conclusion, the lottery method was employed to select one study participant from households with more than one eligible individual (aged 18-65 years old). The selected houses were identified by the supervisors and data collectors few days before the actual data collection. If someone (study subject) was missed from the household during the data collection period, a revisit was done and interviewed.

\section{Data collection}

A pre-tested and structured Amharic version questionnaire was used to collect the data from study subjects via interviewing. The questionnaire was first prepared in English and then translate into Amharic and back to English by different individuals to check consistency and conceptual similarity among the survey teams. The questionnaire was pre-tested (with $10 \%$ of the sample size) before actual data collection in an area not included in the research.

\section{Data quality control}

To ensure the quality of data, two well-trained degree-level supervisors were assigned to assist the data collectors. The investigator directs and monitors the whole data collection process for consistency, completeness, and accuracy. Training of data collectors and supervisor, daily data checkup for completeness and use of the pretested tools were some of the quality assurance measures employed. 


\section{Data processing and analysis}

The collected data were entered and analyzed using SPSS version 20. Binary logistic regression analysis was used to follow the relationship between variables. Descriptive statistics was show results Crude and adjusted odds ratio with $95 \%$ confidence interval was calculated to assess the association between the dependent and independent variables. The level of statistical significance and the ultimate decision was determined based on a p-value of less than 0.05 , AOR at $95 \%$ confidence level.

\section{Result}

\section{Socio-demographic characteristics of the respondents}

A total of 633 participants were sampled and all are interviewed. From The total study participant, 347 respondents are age greater than 25 years (mean age was $30.95 \pm 2.0$ years.). Four hundred sixty-seven (73.8\%) are married. Five hundred-one (79.1\%) of Respondents are educated (more than High school Education). Three hundred seventy-six $376(60 \%)$ of the study participants were Orthodox religion followers, four hundred thirty-seven $437(69 \%)$ were government employees and one hundred forty-Eight $148(23.4 \%)$ were Sidama in ethnicity (table I).

\section{Blood donation practices among study participants}

In this study 633 respondents were responding to the question about the willingness to donate blood.77.4\% are willing to donate blood and the remaining $22.9 \%$ of respondents have at least one-time lifeblood donation experiences.

\section{Reasons for willing to donate blood.}

Most of the respondents were motivated or willing to donate blood for the reason of desire to prevent other, especially when a recipient is family members $513(81 \%)$, considering that blood donation is lifesaving practices $82(13 \%)$ and some of the participant need Momentary gain items $26(4.1 \%)$ such as refreshments, recognition badges, certificates, and clothes (Table II).

Reasons for non-willing to donate blood.

The most frequent affecting factors for not willing to donate blood are Unfit to donate, fear of needle prick, and not approached to donate represent the leading factors $(45.2 \%, 38.5 \%$, and $11.7 \%)$ respectively and Very few people avoid blood donation for lack of time (4.6\%) as shown in. (Table III).

Table-1: Socio-demographic characteristics of the participants $(n=633)$, Hawassa town, Ethiopia 2020. 


\begin{tabular}{|c|c|c|}
\hline Variables & Frequency & Percentage \\
\hline \multicolumn{3}{|l|}{ Age (in years) } \\
\hline$<25$ & 286 & 45.18 \\
\hline$>25$ & 347 & 54.82 \\
\hline \multicolumn{3}{|l|}{ Sex } \\
\hline Female & 212 & 33.5 \\
\hline Male & 421 & 66.5 \\
\hline \multicolumn{3}{|l|}{ Marital Status } \\
\hline Married & 467 & 73.8 \\
\hline Not Married & 166 & 26.2 \\
\hline \multicolumn{3}{|l|}{ Education } \\
\hline Educated & 501 & 79.1 \\
\hline Non-Educated & 132 & 20.9 \\
\hline \multicolumn{3}{|l|}{ Religion } \\
\hline Orthodox & 376 & 59.4 \\
\hline Protestant & 143 & 22.6 \\
\hline Muslim & 81 & 12.8 \\
\hline Catholic & 33 & 5.2 \\
\hline \multicolumn{3}{|l|}{ Occupation } \\
\hline Merchant & 155 & 24.5 \\
\hline Daily Laborer & 41 & 6.5 \\
\hline Government Employee & 437 & 69.0 \\
\hline \multicolumn{3}{|l|}{ Ethnicity } \\
\hline Sidama & 148 & 23.4 \\
\hline Oromo & 130 & 20.5 \\
\hline Gedo & 48 & 7.6 \\
\hline Tigre & 77 & 12.2 \\
\hline Amhara & 113 & 17.9 \\
\hline Gurage & 32 & 5.1 \\
\hline Silte & 14 & 2.2 \\
\hline Wolyita & 65 & 10.9 \\
\hline
\end{tabular}

Table 2: Reason to donate blood ( $\underline{\underline{n}=633}$ ), Hawassa Ethiopia 2020. Reason for donating Frequency Percentage

\begin{tabular}{|c|c|c|}
\hline Desire to help other & 513 & 81 \\
\hline Its Good Practices & 12 & 1.9 \\
\hline Momentary Gain & 26 & 4.1 \\
\hline Its Life Saving & 82 & 13 \\
\hline
\end{tabular}


Table 3: Reason for not donating blood ( $\underline{n}=633)$, Hawassa Ethiopia 2020.

\begin{tabular}{lll}
\cline { 2 - 3 } Reason not donating & Frequency & Percentage \\
\hline Not approached to donate & 74 & 11.7 \\
Unfit to Donate & 286 & 45.2 \\
\hline Fear of Needle & 244 & 38.5 \\
\hline Lack of Time to Donate & 29 & 4.6 \\
\hline
\end{tabular}

1.4 Magnitude of blood donation experiences in relation of socio-demographic characteristic

VARIABLE DONATE $\mathrm{n}(145) \quad$ NOT DONATE, $\mathrm{n}$ (488)

\begin{tabular}{l|cl}
\hline SEX & & \\
MALE & 14 & 370 \\
FEMALE & 10 & 239 \\
AGE & 6 & 150 \\
$<25$ & 31 & 446 \\
$>25$ & & \\
RELIGION & 15 & 192 \\
ORTHODOX & 14 & 100 \\
PROTESTANT & 10 & 150 \\
MUSLIM & 12 & 140 \\
CATHOLIC & & \\
EDUCATION & 15 & 150 \\
NOT EDUCATED & 18 & 450 \\
EDUCATED & &
\end{tabular}

Table 5: Output of Binary logistic regression analysis ( $\underline{n}=633)$, Hawassa Ethiopia, 2020. Tariables Willing to donate blood. COR 95\% CI AOR 95\% CI No Yes 


Female $\quad 3 \quad 418 \quad 3.37(0.8,14.2) * \quad 0.539(0.05,6.2)$

\begin{tabular}{lllllc}
\hline Age & $<25$ & 100 & 205 & 1.0 & \\
\hline Marital Status & 25 & 43 & 285 & $6.1(.75,49.89) *$ & $5.18(0.6,46) * *$ \\
& Not Married 5 & 161 & 1.0 & & \\
& Married & 3 & 464 & $4.8(1.14,20.32) *$ & $1.27(0.1,15)$ \\
\hline Ethnicity & Sidama & 1 & 148 & 1.0 & 2.9 \\
\hline Oromo & 0 & 136 & 1.7 & 1.977 \\
\hline Gedeo & 6 & 48 & 1.7 & 1.731 \\
\hline Tigre & 20 & 77 & 1.7 & $0.2(.025,2.1)$ \\
\hline Amhara & 13 & 110 & $.25(0.025,2.41)$ & $0.307(0.025$ \\
\hline Wolayita & 14 & 60 & $0.11(.012,1.002) *$ & $0.720)$
\end{tabular}

\begin{tabular}{lllll}
\hline Perception to Ward Blood & Bad & 2 & 16 & 1.0
\end{tabular}
donation

Good $\quad 6 \quad 609 \quad 12.687(2.375,67.77) 4.365(0.510$

\begin{tabular}{lllll}
\hline The patient Family Should & No & 6 & 570 & 1.0
\end{tabular}

be asked to donate

$\begin{array}{cccc}\text { Yes } & 2 & 55 & 1.289(0.057,1.46) * \\ & & 0.559(0.073 \\ 4.284)\end{array}$
Motivating Factors
$5 \quad 77 \quad 1.0$

Its life saving

Its good Practices

$\begin{array}{llll}0 & 12 & 9.321 & 1.977\end{array}$

Momentary Gain

$\begin{array}{lll}0 & 26 & 9.32\end{array}$

1.509

Desire to help other

$3 \quad 5101.91(0.021,0.38) * \underset{* *}{2.03(0.028,0.7)}$

COR, crude odds ratio, AOR, adjusted odds ratio $\quad *$ P-value $<=0.25, * *$ P-value $<0.05$

\section{Discussion}

This study has assessed the willingness of blood donation and associated Factors among the Hawassa town population, southern Ethiopia. Accordingly, only $22.9 \%$ of respondents had ever donated blood in their life. Similarly, a study conducted in Addis Ababa University health science students almost similar 
$23.5 \% \& 24 \%(19,18)$ and this result somewhat lower than with the findings of institution-based a crosssectional study conducted among University of Gondar Hospital, Addis Ababa health Facilities and Saudi Army force hospital is $33.2 \%, 32.6 \%, 58.2 \%(12,14,15)$ and this study somewhat higher than studies done in Dhaka in Bangladesh and Nigeria and Madawalabu University Students Ethiopia, 16\%,15.3\%, and $18.4 \%$, respectively $(13,7,16)$.In this study, $77.4 \%$ of the participant are willing to donate blood in the coming future time. In this study, somewhat higher than the study conducted in Nigeria $73 \% \mathrm{c}$, this difference may be due to the study setting, sample size \&differences in study population (17). This study revealed that Age greater than 25 years and Desire to help others, especially family members are Significant predictor variables for willingness to blood donation $54.8 \%$ and $81 \%$ Similarly, a study conducted on Undergraduate Medical Students in Karachi and Nigeria, 55.4\% and 88.3\% $(9,21)$ respectively. This similarity may be due to the study participant demographic characteristic condition. This study revealed that reason for willingness to donate blood is helping family members or relatives, considering that its life saving, and very low proportion of the participant motivated by the momentary gain $(81 \%, 13 \% \& 4.1 \%)$ respectively. Again, in this study unfit to donate, fear of needle prick, and Not approached to do so are major conditions that respondents not willing to donate blood $(45.2 \%, 3.8 \%$ $\$ 11.7 \%)$ respectively $(1,20,11)$.

\section{Conclusion}

Willingness to donate blood was mostly based on the primordial motivation of helping the patient in need which does not translate to blood donation. There is a need to improve awareness and advocacy on blood donation among the Hawassa town population.

\section{Abbreviations}

AOR, Adjusted odds ratio; COR, Crude odds ratio; ERCS, Ethiopian Red Cross Society; MOH, Ministry of Health, NBTS, National blood Transfusion services, WHO, world health Organization, VBD, Voluntary Blood Donation, CSA, Central statistical agency, SPSS: statistical package for social sciences.

\section{Declarations}

Acknowledgments: We would like to thank all study participants who participated in this study for their commitment to responding to our interviews.

\section{Ethics approval and consent to participate.}

The purposes and the importance of the study were explained by the data facilitator to the study participants and written informed consent was secured from each participant. Confidentiality was maintained at all levels of the study by keeping the data in secure places.

\section{Competing interests}


The authors declare that they have no competing interests. Availability of data and materials Datasets will not be shared to protect the participants' confidentiality.

Authors' contributions: BG- wrote the proposal \&drafted the paper, HD participated in data collection YManalyzed the data. All authors read and approved the final manuscript.

\section{References}

1. Dhingra N. World blood donor day: new blood for the world. World Health Organization. 2013.

2. Devi HS, Laishram J, Shantibala K, Elangbai V. Knowledge, attitude, and practice (KAP) of blood safety and donation. Indian Medical Gazette.2012. p. 1-5.

3. Nwogoh B, Aigberadion U, Nwannadi Al. Knowledge, attitude, and practice of voluntary blood donation among healthcare workers at the University of Benin Teaching Hospital, Benin City, Nigeria. J Blood Transfuse. 2013; 2013:1-6.

4. Baig M, Habib H, Haji AH, Alsharief FT, Noor AM, Makki RG. Knowledge, misconceptions, and motivations towards blood donation among university students in Saudi Arabia. Pak J Med Sci. 2013;29(6):1295-9.

5. Karroubi Knowledge attitude and practices of blood donors toward blood donation Postgrad Med Educ Res.2014;48(3)123-7.

6. Manikandan S, Srikumar R, Ruvanthika P. A study on knowledge, attitude, and practice on blood donation among health professional students in Chennai, Tamil Nadu, South India. Int J Sci Res Publ. 2013;3(3):1-4.

7. Salaudeen AG, Odeh E. Knowledge, and behavior towards voluntary blood donation among students of a tertiary institution in Nigeria. Niger J Clin Pract. 2011; 14:303-7.

8. Nigatu A, Demissie DB. Knowledge, attitude, and practice on voluntary blood donation and associated factors among Ambo University Regular Students, Ambo Town, Ethiopia. J Community Med Health Educ. 2014;4(5):6-6.

9. Renzaho A, Polonsky MJ. The influence of acculturation, medical mistrust, and perceived discrimination on knowledge about blood donation and blood donation status: acculturation and blood donation. Transfusion (Paris). 2013; 53:162S-71S.

10. Mikkelsen N. Donor associations, a key link between donors and blood centers. ISBT Sci Ser 5.N1. 2010; 5:12-6.

11. Timothy Colin Bednall, L. L. (2011). Donating Blood: A Meta-Analytic Review of Self-Reported Motivators and Deterrents. Transfusion medicine reviews.

12. Blood donation practice and its associated factors among health professionals of University of Gondar Hospital, Northwest

13. Ethiopia: a cross-sectional study, June 2015. 
14. Mirutse G. Fissha G, Alemayehu M, Abebe L, Birhanu Z. Intention to donate blood among the eligible population in Mekelle City, Northern Ethiopia: Using the theory of planned behavior American Journal of Health Research. 2014;2(4):158-63.

15. BANTAYEHU D 2015. Knowledge, attitude and practice and associated factors of voluntary blood donation among Health care provider in Addis Ababa Health facilities, Ethiopia, Occupy Med Health staff.

16. DEJEN 2015. Knowledge, attitude, practice, and associated factors of blood donation among health care workers in Tikur Ambesa Specialized Hospital, Addis Ababa, Ethiopia.

17. Voluntary Blood Donation Practices and Associated Factors among Regular Undergraduate Madawalabu University Students, Southeast Ethiopia: Birhanu Darega1*, Nagasa Dida2, Tamiru Tesfaye1, and Bikila Lencha2 Sep 22, 2015.

18. A cross-sectional survey of the willingness of tertiary hospital staff to donate blood in Sagamu, Nigeria Jiamusi OA1, Ojo OT*2, Adegoke OM2, Alabi AD1, Sholeye 001, Olatunji 2 vol 2, July-Dec 2016.

19. Dawit malako, Fissehatsion Yoseph and Mebratu Legesse Bekele Assessment of KAP and associated factors of blood donation among health care providers in Ethiopia, 2019.

20. MISGANAW C, TENKIR M, DERESEA A, TESFAYE M, TESHOME T \& HAWULT T 2014. The level and associated factors of knowledge, attitude, and practice of blood donation among health science students at Addis Ababa University.

21. Ahmed Z, Zafar M, Khan AA, Anjum MU, Siddique MA. Knowledge, attitude, and practices about blood donation among undergraduate medical students in Karachi. J Infect Dis Ther, 2014; 2:134.

22. Blood donation practice and its associated factors among health professionals of University of Gondar Hospital, NorthwestEthiopia: a cross-sectional study, June 2015. 